Check for updates

Cite this: J. Mater. Chem. A, 2018, 6, 1181

Received 3rd November 2017

Accepted 14th December 2017

DOI: $10.1039 / c 7 t a 09699 b$

rsc.li/materials-a

\section{Controlling interpenetration through linker conformation in the modulated synthesis of Sc metal-organic frameworks $\uparrow$}

\author{
Ross J. Marshall, (D) a Ciaran T. Lennon, ${ }^{a}$ Andi Tao, ${ }^{b}$ Hans M. Senn, (D) a \\ Claire Wilson, (D) ${ }^{a}$ David Fairen-Jimenez (iD $* b$ and Ross S. Forgan (iD *a
}

\begin{abstract}
Interpenetration in metal-organic frameworks (MOFs), where multiple nets of metal ions or clusters linked by organic ligands are nested within each other's pore spaces, affects important physical properties such as stability and gas uptake, and can be controlled through ligand sterics and modifying synthetic conditions. Herein, we extend the use of coordination modulation - deliberate addition of competing monotopic ligands to syntheses - to prepare Sc MOFs containing related biphenyl-4,4'-dicarboxylate (bpdc) and 2,2'-bipyridine-5,5'-dicarboxylate (bpydc) linkers. The Sc-bpdc MOF adopts a two-fold interpenetrated structure, however, the Sc-bpydc MOF is non-interpenetrated, despite only minor electronic modifications to the ligand. A comprehensive experimental and theoretical examination reveals that ligand twisting (energetically favourable for bpdc but not bpydc) and associated $\pi$-stacking interactions are a prerequisite for interpenetration. The more rigid Sc-bpdc is susceptible to modulation, resulting in differences in morphology, thermal stability and the synthesis of a highly defective, acetate-capped mesoporous material, while the large pore volume of Sc-bpydc allows postsynthetic metallation with $\mathrm{CuCl}_{2}$ in a single-crystal to single-crystal manner. Controlling interpenetration through linker conformation could result in design of new materials with desirable properties such as bifunctional solidstate catalysts.
\end{abstract}

\section{Introduction}

Metal-organic frameworks ${ }^{\mathbf{1 - 4}}$ (MOFs) are network structures of metal ions or clusters connected by organic ligands that have received large amounts of interest in recent years mainly due to their suggested use in applications including gas capture and storage, ${ }^{5-7}$ catalysis $^{8-10}$ and drug delivery ${ }^{\mathbf{1 1 - 1 3}}$ amongst others. Interpenetration - the phenomenon whereby one or more frameworks grow within the void space of the first - can tune both the pore volume and texture, and often results in MOFs with greater structural/chemical stabilities. ${ }^{14-16}$ As such, attempts have been made to control interpenetration through influencing parameters including ligand length, ${ }^{17}$ pendant functionality ${ }^{\mathbf{1 8 , 1 9}}$ and synthesis conditions, ${ }^{\mathbf{2 0 - 2 2}}$ while in extreme cases MOFs with certain topologies (e.g. rht) cannot interpenetrate. $^{23}$ Relatively subtle linker modifications can induce

${ }^{a}$ WestCHEM, School of Chemistry, University of Glasgow, University Avenue, Glasgow, G12 8QQ, UK. E-mail: Ross.Forgan@glasgow.ac.uk

${ }^{b}$ Adsorption \& Advanced Materials Laboratory, Department of Chemical Engineering \& Biotechnology, University of Cambridge, Pembroke Street, Cambridge CB2 3RA, UK. E-mail:df334@cambridge.ac.uk

$\dagger$ Electronic supplementary information (ESI) available: Synthesis and characterisation of MOFs, crystallographic data, all computational simulations and analyses. CCDC 1559284-1559286. For ESI and crystallographic data in CIF or other electronic format see DOI: 10.1039/c7ta09699b. differing structures; in a pair of $\mathrm{Zn}$ MOFs substitution of a ligand $\mathrm{C}-\mathrm{C}$ single bond for a $\mathrm{C}=\mathrm{C}$ double bond is enough to switch from doubly-interpenetrated to non-interpenetrated, ${ }^{24}$ but modifications often require a change in ligand shape or sterics.

Stability can also be improved by using high-valent metals, ${ }^{25}$ for example in MOFs linked by $\mathrm{Zr}^{4+} \cdot{ }^{26,27}$ The kinetic inertness of the metal-oxygen bonds means that coordination modulation the addition of competing monotopic ligands to syntheses - is commonplace to enhance their self-assembly and materials properties, but it is usually done so in a trial and error approach. ${ }^{28-30}$ The modulating agent influences the crystallisation kinetics, most likely by competing with the ligands for attachment to the metal clusters as they assemble in solution. Utilising modulators in MOF syntheses can result in the creation of defects, in the form of missing linkers and/or clusters with concomitant incorporation of capping modulators, which can impart the MOF with interesting and unusual physical properties. $^{31,32}$ Recent studies have shown that modulator incorporation and subsequently defectivity can be correlated to the $\mathrm{p} K_{\mathrm{a}}$ of the modulating agent. ${ }^{30,33}$

Metal ions in the 3+ oxidation state (e.g. $\mathrm{Cr}, \mathrm{Fe}, \mathrm{V}, \mathrm{Al}$ and $\mathrm{Sc}$ ) are well known for forming materials of the so-called MIL (Material Institut Lavoisier) family. ${ }^{34-36}$ Members of this series are known to "breathe"; hinging and rotation around the 
$\left[\mathrm{M}_{3} \mathrm{O}\left(\mathrm{RCO}_{2}\right)_{6}\right]$ secondary building units (SBUs) allows significant swelling or contraction of the MOFs depending on the nature of the guest molecules (or lack thereof) within the pores. ${ }^{34,37,38}$ Much of the attention has been given to $\mathrm{Fe}$ and $\mathrm{Cr}$ derivatives, however, a few examples of Sc MOFs have been reported..$^{39-46}$ The Lewis acidity of $\mathrm{Sc}^{3+}$ makes Sc MOFs excellent candidates for heterogeneous catalysis, with MIL-100(Sc), a scandium trimesate, found to be a particularly efficient catalyst for a range of transformations. ${ }^{42}$ A number of scandium 1,4-benzenedicarboxylate (bdc) MOFs are known, including $\left[\mathrm{Sc}_{2}(\mathrm{bdc})_{3}\right]_{n},{ }^{39} \mathrm{MIL}-88 \mathrm{~B}(\mathrm{Sc})$ with formula $\left[\mathrm{Sc}_{3}\left(\mu_{3^{-}}\right.\right.$ $\left.\mathrm{O})(\mathrm{bdc})_{3}\left(\mathrm{H}_{2} \mathrm{O}\right)_{2} \mathrm{X}\right]_{n}\left(\mathrm{X}=\mathrm{OH}^{-}\right.$or $\left.\mathrm{Cl}^{-}\right){ }^{43,44} \mathrm{MIL}-53(\mathrm{Sc})^{45,46}$ and MIL$68(\mathrm{Sc}),{ }^{42}$ which both have formula $[\mathrm{Sc}(\mathrm{OH})(\mathrm{bdc})]_{n}$. In contrast, $\mathrm{Sc}$ MOFs with extended linkers (Fig. 1a) such as biphenyl-4,4'dicarboxylate (bpdc) and 2,2'-bipyridine-5,5'-dicarboxylate (bpydc) are rare, with the only report of a Sc-bpdc MOF suggesting the formation of a two-fold interpenetrated MIL-88 phase of bpdc ligands linked by $\left[\mathrm{Sc}_{3}\left(\mu_{3}-\mathrm{O}\right)\left(\mathrm{RCO}_{2}\right)_{6}\left(\mathrm{H}_{2} \mathrm{O}\right)_{2} \mathrm{X}\right]$ SBUs (Fig. $\left.1 \mathrm{~b}\right)^{42}$ that is structurally analogous to MIL-126(Fe), which has composition $\left[\mathrm{Fe}_{3}\left(\mu_{3}-\mathrm{O}\right)(\text { bpdc })_{3}\left(\mathrm{H}_{2} \mathrm{O}\right)_{2} \mathrm{X}\right]$ (Fig. 1c). ${ }^{37}$

Driven by our interest in the modulation of $\mathrm{Zr} \mathrm{MOFs}{ }^{13,29,47}$ and the relatively limited research into Sc MOFs in comparison, we sought to extend modulated syntheses to Sc MOFs containing bpdc and bpydc ligands (Fig. 1b) in an attempt to: (i) confirm the structure and level of interpenetration of the reported Sc-bpdc MOF, ${ }^{42}$ (ii) examine the extent of structural diversity, as seen for the Sc-bdc MOFs, in this series, and (iii) control the physical properties of the resulting materials.
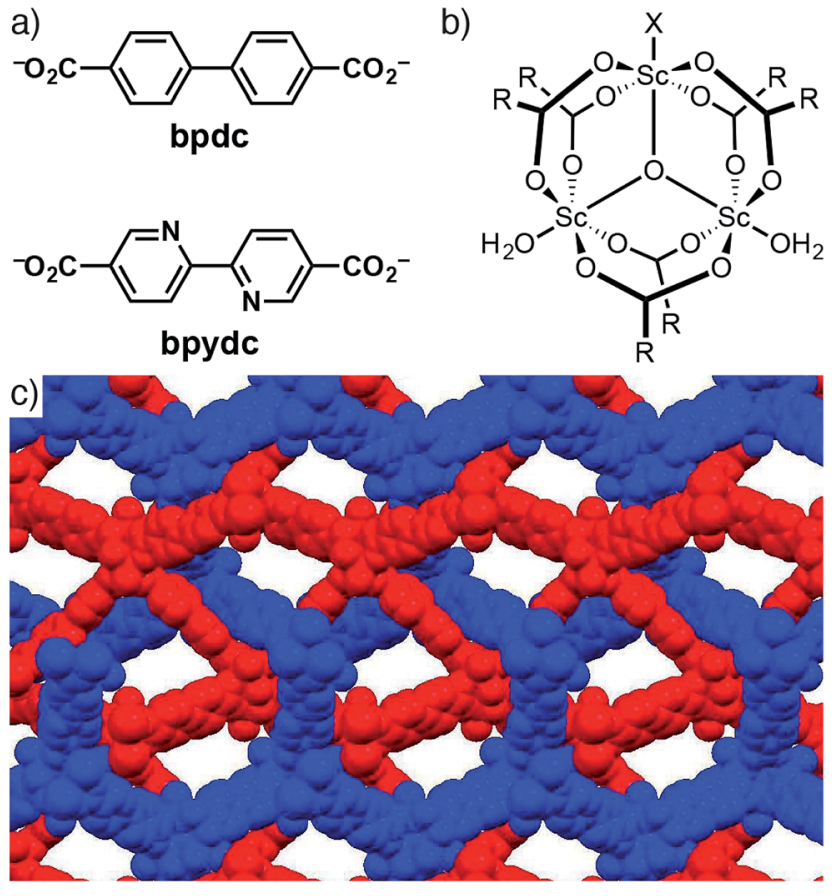

Fig. 1 (a) Chemical structures and abbreviations of the ligands used in this study. (b) Structure of the $\left[\mathrm{SC}_{3}\left(\mu_{3}-\mathrm{O}\right)\left(\mathrm{RCO}_{2}\right)_{6}\left(\mathrm{H}_{2} \mathrm{O}\right)_{2} \mathrm{X}\right]$ secondary building unit found in MIL-88B(SC). (c) Portion of the packing of MIL$126(\mathrm{Fe})$ redrawn from its solid-state structure (CCDC code MIBMER $)^{37}$ in space-filling mode with the two interpenetrating nets coloured red and blue. $\mathrm{H}$ atoms removed for clarity.

\section{Synthesis and modulation of 1}

Initial attempts were focussed on reproducing the synthesis of the Sc-bpdc MOF in an unmodulated synthesis as a control experiment. Solvothermal reaction of one equivalent each of scandium nitrate hydrate and bpdc- $\mathrm{H}_{2}$ in $\mathrm{N}, \mathrm{N}$-dimethylformamide (DMF) at $120{ }^{\circ} \mathrm{C}$ for 24 hours yielded a white powder, compound 1. Powder X-ray diffraction (PXRD, Fig. 2) showed a similar pattern to the previous literature report. Comparison with a pattern predicted from the single crystal structure of the analogous two-fold interpenetrated $\mathrm{Fe}^{3+}$ MOF containing bpdc reported by Serre et al. in 2012 (ref. 37) (MIL-126(Fe), CCDC code MIBMER, also reported by Zhou et al. in 2014 (ref. 48) as PCN245) suggests 1 indeed adopts the two-fold interpenetrated structure, to form MIL-126(Sc), with the overall formula $\left[\mathrm{Sc}_{3}-\right.$ $\left.\mathrm{O}\left(\mathrm{H}_{2} \mathrm{O}\right)_{2}(\mathrm{bpdc})_{3} \mathrm{X}\right]_{n}$ (where $\mathrm{X}=\mathrm{OH}^{-}$or $\left.\mathrm{Cl}^{-}\right)$.

However, low diffraction intensity and the slight differences observed for the high angle data led to attempts to improve crystallinity by modulating the synthesis of $\mathbf{1}$ (see ESI, Section $\mathrm{S} 2 \dagger$ ) with the known modulators hydrochloric acid (one equivalent), ${ }^{49}$ acetic acid (AA, thirty equivalents) ${ }^{28}$ and L-proline (five equivalents). ${ }^{29}$ One equivalent each of scandium nitrate hydrate and bpdc- $\mathrm{H}_{2}$ were combined in DMF, the modulator was added, and then the mixture was sonicated and heated at $120^{\circ} \mathrm{C}$ for 24 hours. The resulting materials, named 1- $\mathrm{HCl}, 1-\mathrm{AA}$ and 1-Lproline to reflect the modulator added to their respective syntheses, were isolated by centrifugation, washed with DMF and acetone, and activated by evacuation of all residual solvents under vacuum. Powder X-ray diffraction (Fig. 2) again suggests that the modulated samples of $\mathbf{1}$ adopt the two-fold interpenetrated arrangement of MIL-126(Fe), and shows unambiguously that modulation enhances crystallinity, albeit there are additional peaks observed at low angles for 1-AA (marked with asterisks in Fig. 2).

Reaction parameters (temperature and concentration) were varied in the quest for single crystals, although under the

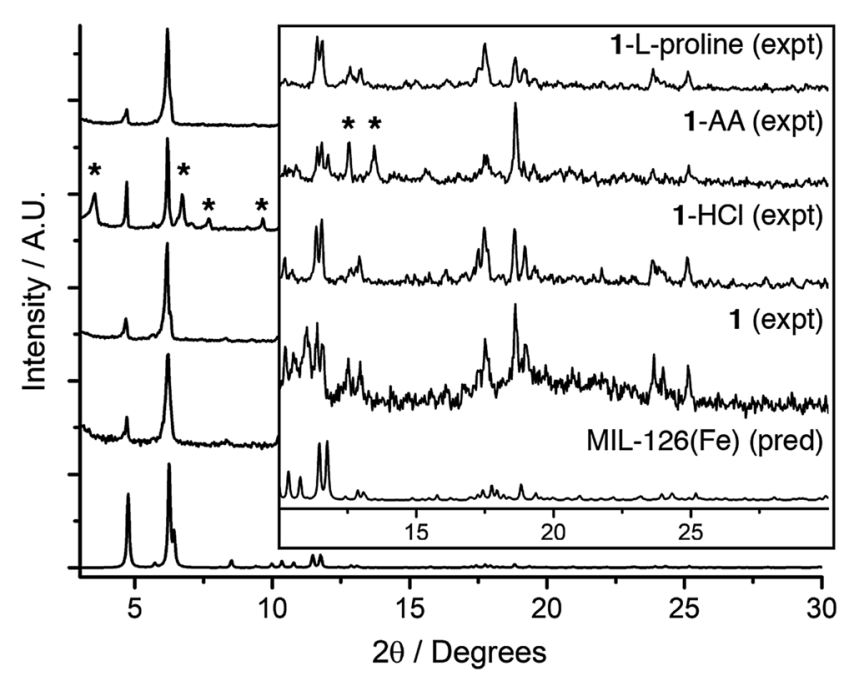

Fig. 2 Stacked PXRD patterns of the Sc-bpdc MOF, 1, prepared with different modulators, compared with the predicted pattern of MIL126(Fe) (CCDC code MIBMER). ${ }^{37}$ 
conditions examined only bulk microcrystalline powders were obtained. Comparing the PXRD patterns of $\mathbf{1}$ with those predicted from the crystal structure of two-fold interpenetrated MIL-126(Fe) and a pattern simulated after removal of one of the interpenetrating nets (see ESI, Fig. S3 $\dagger$ ) again suggests that $\mathbf{1}$ is indeed interpenetrated. Pawley fitting of the PXRD data for 1$\mathrm{HCl}$ (Fig. 3a) gave tetragonal unit cell parameters of $a=21.8044$, $b=c=35.3996 \AA\left(R_{\mathrm{wp}}=8.07 \%\right)$, which are very close to those determined for MIL-126(Fe) and suggest a phase pure material.

Unlike the related non-interpenetrated MIL-88 MOFs, the two-fold interpenetration in $\mathbf{1}$ induces steric restrictions to breathing and thus increases its structural rigidity. $\mathrm{N}_{2}$ adsorption/desorption experiments performed at $77 \mathrm{~K}$ (Fig. 3b) confirm the structural rigidity of $\mathbf{1}$, with the four materials displaying varying levels of porosity (see ESI, Table S3†). The most porous of the four samples is $\mathbf{1}-\mathrm{HCl}$, with a BET area of $1680 \mathrm{~m}^{2} \mathrm{~g}^{-1} \cdot \mathrm{N}_{2}$ adsorption isotherms of 1 and a noninterpenetrated analogue were obtained using grand canonical Monte Carlo (GCMC) simulations (see ESI, Section S4†), with the experimental $\mathrm{N}_{2}$ capacity of 1-HCl at 1 bar slightly lower than that predicted by the simulations - as generally found in GCMC predictions ${ }^{50}$ - but with a good match in the very low pressure region, again suggesting the assignment of two-fold interpenetration is correct. Interestingly, 1-AA displays a Type IV isotherm with a definitive but unexpected mesopore (see ESI, Fig. S5 $\dagger$ ) while the three other materials all display typical Type I isotherms, suggesting the presence of defects within 1-AA.

The physical properties of the samples of 1 were examined by thermogravimetric analysis (TGA) (Fig. 3c). All four materials displayed high thermal stabilities with decomposition observed around $500{ }^{\circ} \mathrm{C}$, while for 1-AA an additional mass loss was observed between $\sim 300-450{ }^{\circ} \mathrm{C} .{ }^{1} \mathrm{H}$ NMR spectroscopy (see ESI, Fig. S8 and S9 $\dagger$ ) of acid digested (DMSO- $d_{6} / \mathrm{D}_{2} \mathrm{SO}_{4}$ ) 1-AA confirms the presence of acetate before and after activation for
$\mathrm{N}_{2}$ uptake experiments, suggesting around $15 \%$ of bpdc ligands are replaced by acetates, and therefore the additional mass loss likely corresponds to its elimination from the MOF. The additional peaks observed in the PXRD of 1-AA, the extra mass loss observed by TGA and the presence of residual acetate in its ${ }^{1} \mathrm{H}$ NMR spectrum, allied with the fact that acetic acid is wellknown to create defects in other early transition metal containing MOFs, infers that 1-AA contains a high concentration of acetate-capped defect sites. ${ }^{30,51}$ Altering the number of equivalents of acetic acid added to syntheses of 1 (ESI, Fig. S10†) showed that mesoporosity (and these defects) occurs when 30 or more equivalents of AA are used, but 60 equivalents retards MOF formation.

Scanning electron microscopy (SEM) images were collected for each of the four MOFs to determine whether modulation had an influence upon crystal morphology (Fig. 3d). The SEM images unambiguously show that the addition of modulators has a significant impact on crystallite morphology, especially for 1-AA where small plates/sheets of material are observed to aggregate to form larger spherical entities, in comparison to the fractured needles of $\mathbf{1}$, agglomerated blocks of $\mathbf{1}-\mathrm{HCl}$ and large, acicular arrangements of 1-L-proline. Modulation of $\mathbf{1}$ has allowed not only confirmation of the interpenetrated structure, but also tuned vital physical properties such as porosity, pore texture and particle morphology.

\section{Synthesis and modulation of 2}

Attempts to synthesise modulated samples of a structurally analogous Sc MOF (termed 2) containing the bpydc ligand using identical conditions to those employed during the syntheses of the samples of 1 were unsuccessful (see ESI, Section S6†). PXRD revealed that $2-\mathrm{HCl}$ (one equivalent of $\mathrm{HCl}$ added to the synthesis) was the only crystalline material after activation
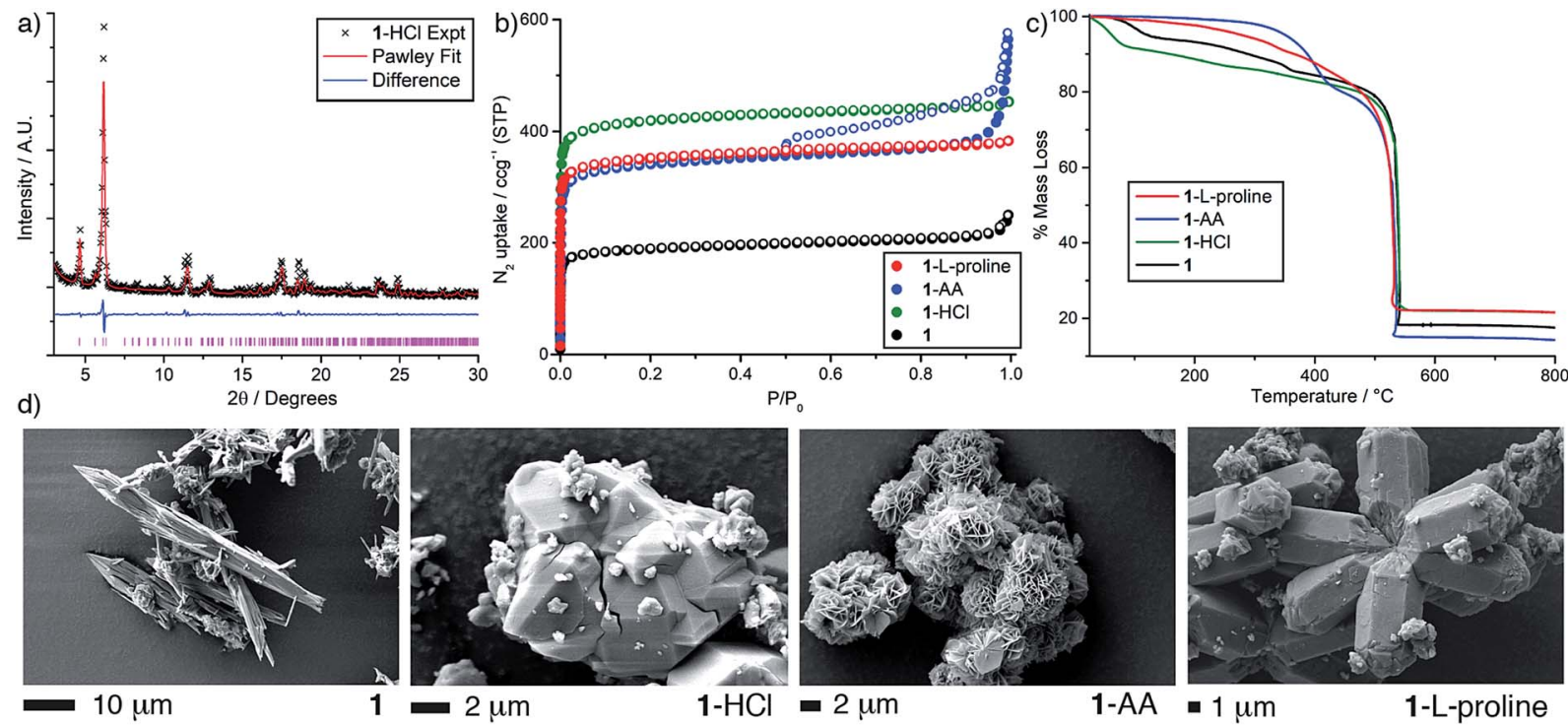

Fig. 3 (a) Pawley fitting of PXRD data for $1-\mathrm{HCl}\left(a=21.8044, b=c=35.3996 \AA ; \alpha=\beta=\gamma=90^{\circ}, R_{\mathrm{wp}}=8.07 \%\right)$. (b) $\mathrm{N}_{2}$ uptake isotherms (77 K) for the modulated samples of 1 . Closed circles indicate adsorption, empty circles desorption. (c) Thermogravimetric analysis (TGA) profiles of the modulated samples of 1 . (d) SEM images of the modulated samples of 1. 
(Fig. 4a), and that it is significantly different from $\mathbf{1}$, despite only minor linker modification. Bulk microcrystalline samples of 2$\mathrm{HCl}$ were analysed by TGA and $\mathrm{N}_{2}$ uptake experiments, revealing that while $2-\mathrm{HCl}$ is thermally stable to $\sim 500{ }^{\circ} \mathrm{C}$ (see ESI, Fig. S16†) it does not display any permanent porosity under these conditions. Single crystals were successfully obtained using $\mathrm{HCl}$ modulation and X-ray diffraction analysis shows that 2-HCl surprisingly adopts the non-interpenetrated MIL-88D topology, ${ }^{36}$ containing $\mathrm{Sc}_{3} \mathrm{O}$ SBUs connected in three dimensions by six bpydc ligands to six neighbouring Sc trimers (Fig. 4b) with an overall formula of $\left[\mathrm{Sc}_{3} \mathrm{O}\left(\mathrm{H}_{2} \mathrm{O}\right)_{2}(\text { bpydc })_{3} \mathrm{X}\right]_{n}$ where $\mathrm{X}$ is expected to be $\mathrm{OH}^{-}$or $\mathrm{Cl}^{-}$to maintain charge neutrality. Non-interpenetrated $2-\mathrm{HCl}$ crystallises in the hexagonal $\mathrm{P6}_{3} / m m c$ space group $(a=17.150(1) \AA, c=25.625(2) \AA)$, in contrast to tetragonal $1-\mathrm{HCl}$. The interior of $2-\mathrm{HCl}$ contains large potential voids (Fig. 4b) that are calculated as $75.7 \%$ of the structure (Mercury 3.9,52 $1.2 \AA$ probe radius, $0.7 \AA$ grid spacing, contact surface) while MIL-126(Fe) (structurally analogous to 1) has a lower void space of $61.1 \%$ due to the two-fold interpenetration.

There are significant differences between the predicted and experimental PXRD patterns of 2-HCl (Fig. 4a) with major peaks moving to higher angles of $2 \theta$, indicating a structural change associated with a smaller unit cell upon desolvation. The presence of additional peaks that may correspond to impurities or breakdown products hampered efforts to find unit cell parameters by fitting the data (see ESI, Section S7†), although the two peaks at low angle could correspond to a hexagonal material with a reduced cell $(a=15.4 \AA, c=19.3 \AA)$. Combined with its apparent non-porosity, this suggests that 2-HCl adopts a closed pore form upon drying. The presence of an impurity phase was confirmed by isolation of a few block-shaped crystals of a third MOF, 3, with formula $\left.\left[\mathrm{Sc}_{2} \text { (bpydc) }\right]_{3}\right]_{n}$, which were also visible by SEM (see ESI, Fig. S15†). 3 is isoreticular to the well-known $\left[\mathrm{Sc}_{2}(\mathrm{bdc})_{3}\right]_{n}$ (bdc $=1,4$-benzenedicarboxylate) series of MOFs (see ESI, Section S8†).

Comparing the PXRD pattern predicted from the crystal structure of $2-\mathrm{HCl}$ with the experimental pattern for $1-\mathrm{HCl}$ again

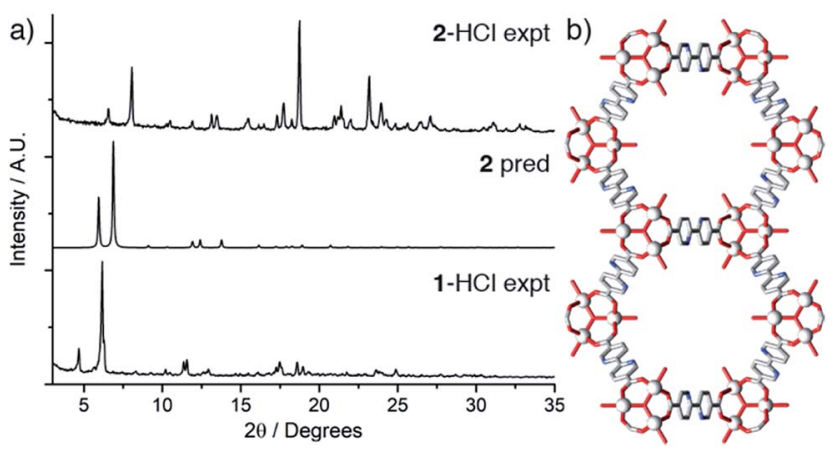

Fig. 4 (a) Comparison of the experimental PXRD patterns of $1-\mathrm{HCl}$ and $2-\mathrm{HCl}$ with the predicted pattern of $2-\mathrm{HCl}$ (from its single crystal structure). (b) Portion of the solid-state structure of $2-\mathrm{HCl}$ viewed down the crystallographic $\mathrm{C}$ axis. Disorder and $\mathrm{H}$ atoms removed for clarity; $\mathrm{C}$ atoms grey, $\mathrm{O}$ atoms red, $\mathrm{N}$ atoms blue, Sc atoms silver spheres. confirms that 1-HCl indeed adopts the two-fold interpenetrated MIL-126(Sc) structure as expected. This structural collapse of 2$\mathrm{HCl}$ is in contrast to the rigidity and porosity observed for the samples of $\mathbf{1}$, with the contrasting structural stabilities a consequence of the differing levels of interpenetration. It was not possible to resolvate 2 - $\mathrm{HCl}$ to any notable extent after drying, in concert with literature reports of similar noninterpenetrated analogues. ${ }^{38}$

\section{Metallation of 2}

Postsynthetic modification (PSM) in general, ${ }^{53-55}$ and specifically metalation of chemically stable MOFs containing free bipy sites, ${ }^{56-62}$ have proven to be highly efficient methods to enhance the properties of MOFs, and so we attempted metallation of $2-\mathrm{HCl}$ with $\mathrm{CuCl}_{2}$ as a proof-of-concept transformation with the aim of introducing group 10 metals for catalytic applications, as well as potentially adding suitable steric bulk to stop the material adopting a closed pore form on drying (see ESI, Section S9†). Single crystals of 2 - $\mathrm{HCl}$ were metallated by immersion in an anhydrous DMF solution containing $\mathrm{CuCl}_{2}$ at $60{ }^{\circ} \mathrm{C}$ for 42 hours. Colourless crystals of 2-HCl turned light green on metallation, suggesting successful formation of the metallated $\mathrm{MOF}, 2-\mathrm{CuCl}_{2}$. X-Ray diffraction confirmed that $2-\mathrm{HCl}$ was successfully transformed to $2-\mathrm{CuCl}_{2}$ in a single crystal-to-single crystal (SCSC) manner (Fig. 5), although the $\mathrm{CuCl}_{2}$ occupancy refines to $50 \%$ and suggests only partial metallation. A change of symmetry is apparent the space group changes from $P 6_{3} / m m c$ to $P \overline{6} 2 c$ - and metallation removes the inherent disorder in the bipyridine units. The analogous reaction was performed on bulk samples, however PXRD revealed that the green powder of $2-\mathrm{CuCl}_{2}$ was not crystalline or porous under the conditions examined, potentially adopting a partially closed pore form upon drying. Although quantitative metallation would not be required for catalytic applications, the structural collapse of both the parent and metallated MOF precluded attempts at bimetallic catalysis, as the apparent instability would complicate handling of the solid state catalyst and raise doubt over its recyclability and usefulness.

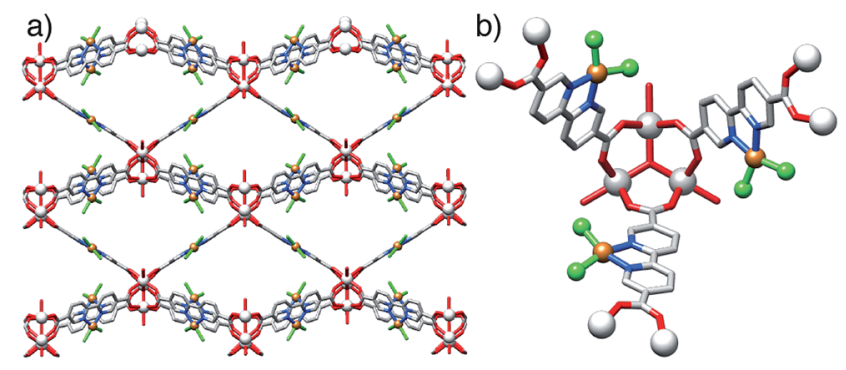

Fig. 5 The solid-state structure of $2-\mathrm{CuCl}_{2}$ showing (a) the packing arrangement of metallated bpydc ligands, and (b) the ordering of metallation around the $\mathrm{SC}_{3} \mathrm{O} \mathrm{SBU}$. $\mathrm{H}$ atoms removed for clarity, all partially occupied $\mathrm{CuCl}_{2}$ positions displayed; $\mathrm{C}$ atoms grey, $\mathrm{O}$ atoms red, $\mathrm{N}$ atoms blue, $\mathrm{Cl}$ atoms green spheres, Sc atoms silver spheres; $\mathrm{Cu}$ atoms bronze spheres. 


\section{Interpenetration control}

The two ligands, bpdc and bpydc, are geometric analogues, and if the substitution of two $\mathrm{C}-\mathrm{H}$ units for two $\mathrm{N}$ atoms and vice versa is ignored then 1 can be understood to be a two-fold interpenetrated derivative of 2 . Considering the structural and chemical similarities of the ligands it would be difficult to predict that such minor electronic modification would impart significant structural differences in the resulting MOFs. Indeed, isostructural MOFs where bpdc linkers are replaced by bpydc have been reported for $\mathrm{Zn}^{2+},{ }^{63} \mathrm{Al}^{3+},{ }^{56}$ and $\mathrm{Zr}^{4+}$, ${ }^{57,64}$ amongst others. In the crystal structure of MIL-126(Fe), which is a structural isomer of $\mathbf{1}$, the three independent bpdc ligands that extend from each $\mathrm{Fe}_{3} \mathrm{O}$ cluster adopt twisted conformations. The rotation of each of the three crystallographically independent bpdc ligands away from co-planarity can be quantified as the average of the four $\mathrm{C}-\mathrm{C}-\mathrm{C}-\mathrm{C}$ torsion angles around each biaryl linkage. Two of the ligands adopt twisted conformations, with average torsion angles between their aromatic rings of $41.3^{\circ}$ and $36.7^{\circ}$ (Fig. 6a) to facilitate $\pi$-stacking interactions between the two interpenetrating nets at a distance of $3.63 \AA$ between the centroids of the aromatic rings and with an angle of $14.7^{\circ}$ between their planes. The third ligand is twisted by $13.8^{\circ}$ and is not involved in $\pi$-stacking between the nets. Ligand twisting is a prerequisite for the $\pi$-stacking interactions by allowing them to become correctly aligned and we believe this stabilising interaction is one of the driving forces for the formation of a two-fold interpenetrated structure; $\pi$-stacking has previously been determined as the driving force for full and partial interpenetration in $\mathrm{Zn}^{2+}$ MOFs of substituted bpdc ligands. ${ }^{22}$ In contrast, the bpydc ligands in the solid-state structure of $2-\mathrm{HCl}$ are effectively co-planar with an average torsion angle of $0.5^{\circ}$ (Fig. 6b), a conformation which is expected to be more energetically favourable for bpydc than the twisted arrangement that is necessary to form the interpenetrated structure of $\mathbf{1}$, and may explain the formation of 2 instead.

To probe this hypothesis further, torsion angles from 2950 biphenyl and 1243 bipyridyl fragment containing structures were mined from the Cambridge Structural Database ${ }^{65}$ using
Conquest 3.9 (ref. 52) (see ESI, Section S10†) and plotted in Fig. $6 \mathrm{c}$ and d. It is clear that while bipyridine units preferentially adopt co-planar conformations, as in 2, biphenyl moieties most commonly twist to give torsion angles in the range of $30-40^{\circ}$, in close agreement with the $\pi$-stacked arrangements in MIL126(Fe) and 1. DFT calculations (M06-2X/def2-TZVP) on disodiated linkers confirm this observation (see ESI, Section $\mathrm{S} 11 \dagger$ ); the energy-minimised structure of $\mathrm{Na}_{2}$ bpdc has a C-C-C$\mathrm{C}$ torsion angle of $38^{\circ}$, while the optimised structure of $\mathrm{Na}_{2}-$ bpydc has a $\mathrm{N}-\mathrm{C}-\mathrm{C}-\mathrm{N}$ torsion angle of $180^{\circ}$, i.e., it is coplanar. Significant energy penalties for deviation from these conformations are observed in the torsion angle profiles (Fig. 6e). We hypothesise that the unfavourable twisting of bpydc would not be compensated for by the favourable $\pi$-stacking interaction and hence 2 remains non-interpenetrated. This is further evidenced upon inspection of the solid state structure of $\mathbf{3}$ (see ESI Section $\mathrm{S} 8 \dagger$ ), with formula $\left[\mathrm{Sc}_{2}(\mathrm{bpydc})_{3}\right]_{n}$, which shows that the bpydc ligands again adopt conformations close to co-planarity (average torsion angles of $0.6^{\circ}, 1.9^{\circ}$ and $7.3^{\circ}$ for three independent ligands in the unit cell). A similar effect has been observed previously in a pair of Mn MOFs linked by tripodal tetrazolate linkers; substitution of benzene for triazine at the ligand core results in a planar ligand that, in this case, promotes interpenetration. ${ }^{66}$

In conclusion, the coordination modulation approach has been successfully applied to Sc MOFs, controlling both the morphology and porosity of a bpdc linked interpenetrated MIL126(Fe) analogue, 1. Replacement of two C-H groups for two N atoms on the ligand has been observed to effectively 'turn-off' interpenetration by disfavouring ligand twisting and structuredirecting $\pi$-stacking, forming the non-interpenetrated MIL-88D analogue, 2, and small amounts of 3 . This is a rare example of interpenetration control through altering ligand electronic structure, rather than by adding or removing steric bulk, which could open up routes to materials with novel topologies and properties. The two-fold interpenetration of 1 results in a rigid material that is susceptible to modulation, tuning particle size and morphology, while $\mathbf{1}$ is stable enough to allow the induction of hierarchical porosity through controlled defect formation.
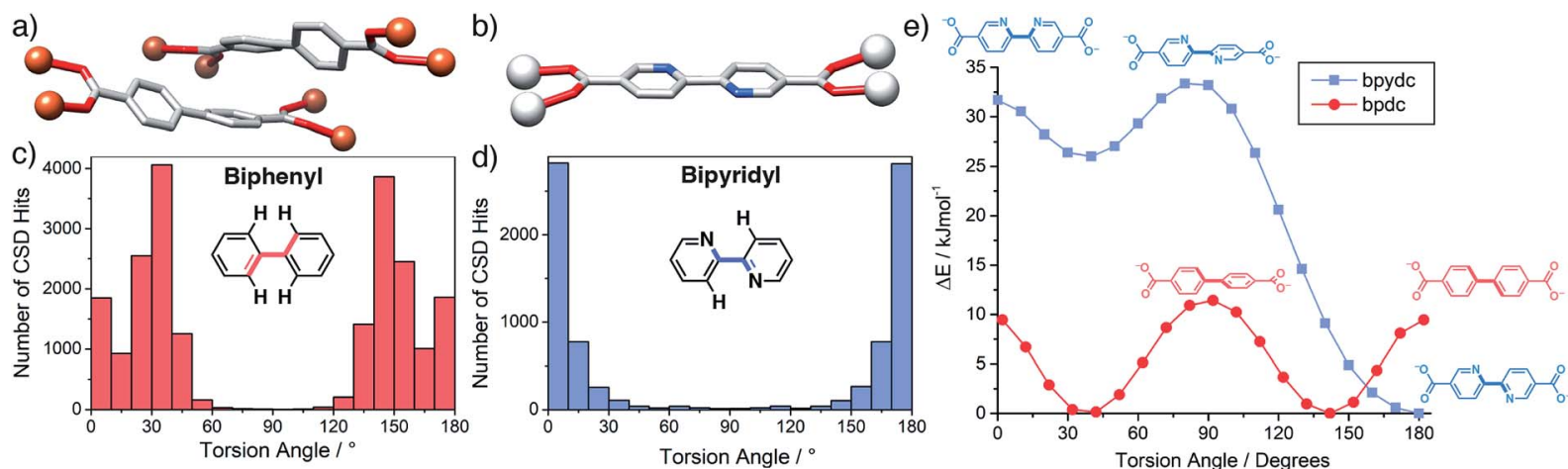

Fig. 6 (a) Twisting of bpdc ligands in the solid-state structure of MIL-126(Fe) to facilitate $\pi$-stacking (CCDC code MIBMER). ${ }^{37}$ (b) Linear arrangement of bpydc in the solid-state structure of $2-\mathrm{HCl}$. Torsion angles in (c) biphenyl and (d) bipyridyl fragments mined from the Cambridge Structural Database. Note that all four torsion angles around the 1-1' linkage are included for each fragment, resulting in symmetrical profiles. (e) Torsional energy profiles for rotation around the 1-1' linkages of di-sodiated bpdc and bpydc linkers calculated by DFT (M06-2X/def2-TZVP). 
The more open structure of 2 contains free $\mathrm{N}$-donors that can be metallated which, combined with the Lewis acidic $\mathrm{Sc}^{3+}$ SBUs, could facilitate the controlled assembly of bifunctional heterogeneous MOF catalysts.

\section{Note}

The data which underpin this work are available at http:// dx.doi.org/10.5525/gla.researchdata.561.

\section{Conflicts of interest}

There are no conflicts of interest to declare.

\section{Acknowledgements}

RSF and DFJ thank the Royal Society for receipt of University Research Fellowships. The research was supported by the University of Glasgow, EPSRC (EP/L004461/1) and ERC (677289, SCoTMOF, ERC-2015-STG, RSF; 726380, NanoMOFdeli, ERC2016-COG, DFJ). Simulations were performed using the Darwin Supercomputer of the University of Cambridge High Performance Computing Service. We thank the EPSRC UK National Crystallographic Service for single crystal data collections. ${ }^{67} \dagger$

\section{References}

1 B. F. Hoskins and R. Robson, J. Am. Chem. Soc., 1990, 112, 1546-1554.

2 G. Ferey, Chem. Soc. Rev., 2008, 37, 191-214.

3 J. R. Long and O. M. Yaghi, Chem. Soc. Rev., 2009, 38, 12131214.

4 H.-C. Zhou, J. R. Long and O. M. Yaghi, Chem. Rev., 2012, 112, 673-674.

5 J.-R. Li, R. J. Kuppler and H.-C. Zhou, Chem. Soc. Rev., 2009, 38, 1477-1504.

6 K. Sumida, D. L. Rogow, J. A. Mason, T. M. McDonald, E. D. Bloch, Z. R. Herm, T.-H. Bae and J. R. Long, Chem. Rev., 2012, 112, 724-781.

7 M. P. Suh, H. J. Park, T. K. Prasad and D.-W. Lim, Chem. Rev., 2012, 112, 782-835.

8 J. Lee, O. K. Farha, J. Roberts, K. A. Scheidt, S. T. Nguyen and J. T. Hupp, Chem. Soc. Rev., 2009, 38, 1450-1459.

9 M. Yoon, R. Srirambalaji and K. Kim, Chem. Rev., 2012, 112, 1196-1231.

10 J. Liu, L. Chen, H. Cui, J. Zhang, L. Zhang and C.-Y. Su, Chem. Soc. Rev., 2014, 43, 6011-6061.

11 P. Horcajada, C. Serre, M. Vallet-Regí, M. Sebban, F. Taulelle and G. Férey, Angew. Chem., Int. Ed., 2006, 45, 5974-5978.

12 P. Horcajada, T. Chalati, C. Serre, B. Gillet, C. Sebrie, T. Baati, J. F. Eubank, D. Heurtaux, P. Clayette, C. Kreuz, J.-S. Chang, Y. K. Hwang, V. Marsaud, P.-N. Bories, L. Cynober, S. Gil, G. Ferey, P. Couvreur and R. Gref, Nat. Mater., 2010, 9, 172-178.

13 I. Abánades Lázaro, S. Haddad, S. Sacca, C. Orellana-Tavra, D. Fairen-Jimenez and R. S. Forgan, Chem, 2017, 2, 561-578.
14 G.-P. Yang, L. Hou, L.-F. Ma and Y.-Y. Wang, CrystEngComm, 2013, 15, 2561-2578.

15 H.-L. Jiang, T. A. Makal and H.-C. Zhou, Coord. Chem. Rev., 2013, 257, 2232-2249.

16 Y.-N. Gong, D.-C. Zhong and T.-B. Lu, CrystEngComm, 2016, 18, 2596-2606.

17 J. Lippke, B. Brosent, T. von Zons, E. Virmani, S. Lilienthal, T. Preuße, M. Hülsmann, A. M. Schneider, S. Wuttke, P. Behrens and A. Godt, Inorg. Chem., 2017, 56, 748-761.

18 O. K. Farha, C. D. Malliakas, M. G. Kanatzidis and J. T. Hupp, J. Am. Chem. Soc., 2010, 132, 950-952.

19 R. K. Deshpande, G. I. N. Waterhouse, G. B. Jameson and S. G. Telfer, Chem. Commun., 2012, 48, 1574-1576.

20 J. H. Park, W. R. Lee, Y. Kim, H. J. Lee, D. W. Ryu, W. J. Phang and C. S. Hong, Cryst. Growth Des., 2014, 14, 699-704.

21 O. Shekhah, H. Wang, M. Paradinas, C. Ocal, B. Schupbach, A. Terfort, D. Zacher, R. A. Fischer and C. Woll, Nat. Mater., 2009, 8, 481-484.

22 A. Ferguson, L. Liu, S. J. Tapperwijn, D. Perl, F.-X. Coudert, S. Van Cleuvenbergen, T. Verbiest, M. A. van der Veen and S. G. Telfer, Nat. Chem., 2016, 8, 250-257.

23 O. K. Farha, I. Eryazici, N. C. Jeong, B. G. Hauser, C. E. Wilmer, A. A. Sarjeant, R. Q. Snurr, S. T. Nguyen, A. Ö. Yazaydın and J. T. Hupp, J. Am. Chem. Soc., 2012, 134, 15016-15021.

24 T. K. Prasad and M. P. Suh, Chem.-Eur. J., 2012, 18, 86738680.

25 T. Devic and C. Serre, Chem. Soc. Rev., 2014, 43, 6097-6115.

26 Y. Bai, Y. Dou, L.-H. Xie, W. Rutledge, J.-R. Li and H.-C. Zhou, Chem. Soc. Rev., 2016, 45, 2327-2367.

27 J. H. Cavka, S. Jakobsen, U. Olsbye, N. Guillou, C. Lamberti, S. Bordiga and K. P. Lillerud, J. Am. Chem. Soc., 2008, 130, 13850-13851.

28 A. Schaate, P. Roy, A. Godt, J. Lippke, F. Waltz, M. Wiebcke and P. Behrens, Chem.-Eur. J., 2011, 17, 6643-6651.

29 R. J. Marshall, C. L. Hobday, C. F. Murphie, S. L. Griffin, C. A. Morrison, S. A. Moggach and R. S. Forgan, J. Mater. Chem. A, 2016, 4, 6955-6963.

30 G. C. Shearer, S. Chavan, S. Bordiga, S. Svelle, U. Olsbye and K. P. Lillerud, Chem. Mater., 2016, 28, 3749-3761.

31 T. D. Bennett, A. K. Cheetham, A. H. Fuchs and F.-X. Coudert, Nat. Chem., 2017, 9, 11-16.

32 Z. Fang, B. Bueken, D. E. De Vos and R. A. Fischer, Angew. Chem., Int. Ed., 2015, 54, 7234-7254.

33 W. Morris, S. Wang, D. Cho, E. Auyeung, P. Li, O. K. Farha and C. A. Mirkin, ACS Appl. Mater. Interfaces, 2017, 9, 33413-33418.

34 C. Serre, F. Millange, C. Thouvenot, M. Noguès, G. Marsolier, D. Louër and G. Férey, J. Am. Chem. Soc., 2002, 124, 1351913526.

35 P. Horcajada, S. Surble, C. Serre, D.-Y. Hong, Y.-K. Seo, J.-S. Chang, J.-M. Greneche, I. Margiolaki and G. Ferey, Chem. Commun., 2007, 2820-2822.

36 S. Surble, C. Serre, C. Mellot-Draznieks, F. Millange and G. Ferey, Chem. Commun., 2006, 284-286.

37 M. Dan-Hardi, H. Chevreau, T. Devic, P. Horcajada, G. Maurin, G. Férey, D. Popov, C. Riekel, S. Wuttke, 
J.-C. Lavalley, A. Vimont, T. Boudewijns, D. de Vos and C. Serre, Chem. Mater., 2012, 24, 2486-2492.

38 C. Serre, C. Mellot-Draznieks, S. Surblé, N. Audebrand, Y. Filinchuk and G. Férey, Science, 2007, 315, 1828.

39 S. R. Miller, P. A. Wright, C. Serre, T. Loiseau, J. Marrot and G. Ferey, Chem. Commun., 2005, 3850-3852.

40 J. Perles, M. Iglesias, C. Ruiz-Valero and N. Snejko, Chem. Commun., 2003, 346-347.

41 F. Gandara, B. Gomez-Lor, M. Iglesias, N. Snejko, E. Gutierrez-Puebla and A. Monge, Chem. Commun., 2009, 2393-2395.

42 L. Mitchell, B. Gonzalez-Santiago, J. P. S. Mowat, M. E. Gunn, P. Williamson, N. Acerbi, M. L. Clarke and P. A. Wright, Catal. Sci. Technol., 2013, 3, 606-617.

43 I. A. Ibarra, X. Lin, S. Yang, A. J. Blake, G. S. Walker, S. A. Barnett, D. R. Allan, N. R. Champness, P. Hubberstey and M. Schröder, Chem.-Eur. J., 2010, 16, 13671-13679.

44 P. D. C. Dietzel, R. Blom and H. Fjellvag, Dalton Trans., 2006, 2055-2057.

45 J. P. S. Mowat, V. R. Seymour, J. M. Griffin, S. P. Thompson, A. M. Z. Slawin, D. Fairen-Jimenez, T. Duren, S. E. Ashbrook and P. A. Wright, Dalton Trans., 2012, 41, 3937-3941.

46 J. P. S. Mowat, S. R. Miller, A. M. Z. Slawin, V. R. Seymour, S. E. Ashbrook and P. A. Wright, Microporous Mesoporous Mater., 2011, 142, 322-333.

47 C. L. Hobday, R. J. Marshall, C. F. Murphie, J. Sotelo, T. Richards, D. R. Allan, T. Düren, F.-X. Coudert, R. S. Forgan, C. A. Morrison, S. A. Moggach and T. D. Bennett, Angew. Chem., Int. Ed., 2016, 55, 2401-2405.

48 D. Feng, K. Wang, Z. Wei, Y.-P. Chen, C. M. Simon, R. K. Arvapally, R. L. Martin, M. Bosch, T.-F. Liu, S. Fordham, D. Yuan, M. A. Omary, M. Haranczyk, B. Smit and H.-C. Zhou, Nat. Commun., 2014, 5, 5723.

49 M. J. Katz, Z. J. Brown, Y. J. Colon, P. W. Siu, K. A. Scheidt, R. Q. Snurr, J. T. Hupp and O. K. Farha, Chem. Commun., 2013, 49, 9449-9451.
50 D. Fairen-Jimenez, R. Galvelis, A. Torrisi, A. D. Gellan, M. T. Wharmby, P. A. Wright, C. Mellot-Draznieks and T. Duren, Dalton Trans., 2012, 41, 10752-10762.

$51 \mathrm{H}$. Wu, Y. S. Chua, V. Krungleviciute, M. Tyagi, P. Chen, T. Yildirim and W. Zhou, J. Am. Chem. Soc., 2013, 135, 10525-10532.

52 I. J. Bruno, J. C. Cole, P. R. Edgington, M. Kessler, C. F. Macrae, P. McCabe, J. Pearson and R. Taylor, Acta Crystallogr., Sect. B: Struct. Sci., 2002, 58, 389-397.

53 S. M. Cohen, J. Am. Chem. Soc., 2017, 139, 2855-2863.

54 R. J. Marshall and R. S. Forgan, Eur. J. Inorg. Chem., 2016, 4310-4331.

55 S. M. Cohen, Chem. Rev., 2012, 112, 970-1000.

56 E. D. Bloch, D. Britt, C. Lee, C. J. Doonan, F. J. Uribe-Romo, H. Furukawa, J. R. Long and O. M. Yaghi, J. Am. Chem. Soc., 2010, 132, 14382-14384.

57 M. I. Gonzalez, E. D. Bloch, J. A. Mason, S. J. Teat and J. R. Long, Inorg. Chem., 2015, 54, 2995-3005.

$58 \mathrm{X}$. Yu and S. M. Cohen, Chem. Commun., 2015, 51, 98809883.

59 K. Manna, T. Zhang, F. X. Greene and W. Lin, J. Am. Chem. Soc., 2015, 137, 2665-2673.

60 Z.-M. Zhang, T. Zhang, C. Wang, Z. Lin, L.-S. Long and W. Lin, J. Am. Chem. Soc., 2015, 137, 3197-3200.

61 Y. Zhou and B. Yan, Chem. Commun., 2016, 52, 2265-2268.

62 T. Zhang, K. Manna and W. Lin, J. Am. Chem. Soc., 2016, 138, 3241-3249.

63 P. V. Dau, M. Kim, S. J. Garibay, F. H. L. Münch, C. E. Moore and S. M. Cohen, Inorg. Chem., 2012, 51, 5671-5676.

64 H. Fei and S. M. Cohen, Chem. Commun., 2014, 50, 48104812.

65 C. R. Groom, I. J. Bruno, M. P. Lightfoot and S. C. Ward, Acta Crystallogr., Sect. B: Struct. Sci., Cryst. Eng. Mater., 2016, 72, 171-179.

66 M. Dincă, A. Dailly, C. Tsay and J. R. Long, Inorg. Chem., 2008, 47, 11-13.

67 S. J. Coles and P. A. Gale, Chem. Sci., 2012, 3, 683-689. 